\title{
Management of Acute Viral Encephalitis in Brazil
}

\author{
Renan Barros Domingues ${ }^{1,2}$ and Antônio Lúcio Teixeira ${ }^{2,3,4}$ \\ ${ }^{1}$ Department of Pathology, School of Health Sciences of Santa Casa de Vitória [EMESCAM], Vitória, Espírito Santo; ${ }^{2}$ Neurosciences \\ Postgraduation Program, Federal University of Minas Gerais [UFMG]; ${ }^{3}$ Infectious Diseases and Tropical Medicine Postgraduation Program, \\ Federal University of Minas Gerais [UFMG]; ${ }^{4}$ Department of Internal Medicine, School of Medicine, Federal University of Minas Gerais \\ [UFMG], Belo Horizonte, MG, Brazil
}

\begin{abstract}
The appropriate management of acute viral encephalitis is a challenge. Clinical picture includes general symptoms and a wide range of neurological signs. Etiological diagnosis cannot be performed only by clinical means and depends on neuroimaging studies and cerebrospinal fluid molecular analyses. It is recommended since some of these viruses are treatable and that the prognoses of these infections depend on the prompt administration of antiviral and/or immunomodulatory drugs. The management of acute viral encephalitis in Brazil has some peculiarities. First, the etiological distribution of the viral encephalitis may differ from what is found in other countries. Some viruses, such as dengue virus, are more common in Brazil than in developed countries while others, like West Nile virus, are not found here. Second, there are some regions in Brazil where neuroimaging and laboratorial methods are not available, and a clinical-based decision is the only therapeutic approach. As most of the guidelines in the literature are based on complimentary methods, it is relevant to establish an alternative approach compatible with the Brazilian health system reality. The goal of this study was to review the recent advances in the field of the acute viral encephalitis, to discuss the diagnosis and the treatment of the main etiologies of acute viral encephalitis found in Brazil, and to propose a viable guideline for the evaluation of the suspected acute viral encephalitis cases in the emergence room in Brazil.
\end{abstract}

Key-Words: Acute viral encephalitis, cerebrospinal fluid, neuroimaging, clinical management.

Several viruses may cause acute central nervous system (CNS) diseases with a broad range of clinical manifestations. These symptoms may result from two distinct physiopathological mechanisms. The first is due to direct viral entry into the CNS leading to neuronal damaging. The second mechanism is triggered by systemic viral infections leading to postinfectious autoimmune response inside the CNS [1].

Acute viral encephalitis may affect healthy individuals and opportunistic viruses can cause encephalitis in immunocompromised hosts [2]. The epidemiology of acute viral encephalitis has been changing in recent decades. Opportunistic infections of the brain have been seen more frequently because of the increasing number of immunocompromised patients. Moreover evolving lifestyles and ecological changes have lead to recent outbreaks of viral encephalitis, including arthropod-borne virus encephalitis $[3,4]$.

Many scientific achievements in neuroimaging, molecular diagnosis, antiviral therapy, immunomodulatory treatments, and neurointensive care have allowed more precise and earlier diagnoses as more efficient treatments, resulting in improved outcomes [2].

In this article, we perform a narrative review of the most important acute viral etiologies encephalitis in Brazil. Also, we propose a practical approach for the management of suspected acute viral encephalitis in the emergence room.

Received on 17 April 2009; revised 10 July 2009.

Address for correspondence: Dr. Renan Barros Domingues. Rua Professor Almeida Cousin, 125, sala 1310. Zip code: 29055-565. Vitória-ES, Brazil. Phone: (27) 3345-7056. E-mail: contato@renandomingues.med.br.

The Brazilian Journal of Infectious Diseases 2009;13(6):433-439. (C) 2009 by The Brazilian Journal of Infectious Diseases and Contexto Publishing. All rights reserved.

\section{Clinical Presentation}

The clinical picture of acute viral encephalitis usually begins with acute systemic symptoms, such as fever, nausea and vomiting, followed by a wide range of neurological signs and symptoms. In a neurological perspective, three distinct pictures of acute encephalitis can be defined: focal, diffuse, and mild $[5,6]$.

Focal encephalitis results from neuronal spread of the virus $[7,8]$. Its usual manifestations comprise focal seizures and localizing symptoms, including motor deficits (reflecting motor cortex or pyramidal tract involvement); aphasia (reflecting left hemisphere temporal or frontal cortex involvement); personality and behavioral changes (reflecting frontal and medial temporal involvement); visual field deficits (reflecting temporal, parietal or occipital involvement); cranial nerve deficits (reflecting brainstem involvement).

Diffuse encephalitis results from hematogenous spread of the virus that crosses the blood brain barrier through ependimal cells [6]. Clinical picture of diffuse encephalitis include mental status changes and generalized seizures. Both focal and diffuse encephalitis may lead to intracranial hypertension. When the encephalitis reaches this stage the patients become comatose and intensive care is required.

Mild encephalitis is focal or diffuse encephalitis without significant arousal compromise and with normal neurological examination after recovery [5].

Upon the suspicion of acute viral encephalitis, a prompt neurological evaluation must ensue along with neuroimaging study and cerebrospinal fluid (CSF) analysis. When available, polymerase chain reaction tests must be performed to establish the etiology of acute encephalitis [2,9]. 


\section{Main Causes of Viral Encephalitis}

Herpes Simplex Encephalitis [HSE]

Herpes simplex virus (HSV) is the most frequently diagnosed acute viral encephalitis. It has an annual incidence of 1 in 250.000 to 500.000 [9]. Nearly 95\% of the cases are associated with HSV-1 and the remaining cases are associated with HSV-2 [10,11].

Herpes simplex encephalitis (HSE) usually occurs in immunocompetent hosts [11]. The clinical picture is usually of focal encephalitis, but in rare cases, mild or diffuse encephalitis may occur. Although brain biopsy was required in the past to confirm HSE, the diagnosis can be achieved now by non-invasive methods [11].

Neuroimaging tests are extremely helpful, especially magnetic resonance imaging (MRI). MRI usually shows cortical and white matter lesions in inferomedial temporal lobe, superficial temporal cortex, insular gyrus, rectus gyrus, and cingulate gyrus in more than $90 \%$ of the cases [12]. Computerized tomography (CT) is less sensitive and shows temporal abnormalities in approximately $50 \%$ of the cases [5]. Serum and CSF antibody testing are not useful since antiHSV IgG antibodies are seen in healthy individuals and may reflect a latent infection $[10,11]$.

Etiological diagnosis can be confirmed by PCR in a CSF sample with an overall sensitivity and specificity above $95 \%$ $[11,13,14]$. Moreover, as reported by Domingues et al., quantitative PCR was shown to be a promising assay in the prognostic evaluation of HSE patients [15]. In that study, viral CSF loads above 100 HSV DNA copies per micro liter were related with a poorer prognosis when compared to lower CSF viral loads [15].

The current drug for the therapy of HSE is intravenous acyclovir [16-21]. Acyclovir is used in a dosage of $10 \mathrm{mg} / \mathrm{Kg}$ every 8 hours for a period of 21 days. The HSE mortality was reduced from $70 \%$ to less than $20 \%$ with acyclovir [21]. Nearly half of the patients who survive still have a neurological impairment six months after the completion of therapy $[17,21]$. Severe adverse effects with this drug are not frequent; however, increased levels of hepatic enzymes and increased levels of blood nitrogen may be seen [18]. HSV resistance to this drug in HSE patients has been very rarely reported, but it may occur, especially in immunocompromised hosts [22,23].

About $5 \%$ to $10 \%$ of patients may reactivate encephalitic symptoms after antiviral treatment [21]. The use of oral valaciclovir for three months after acyclovir treatment is currently being evaluated to prevent HSE recurrences $[21,24,25]$.

\section{Varicella-Zoster Encephalitis}

The most common CNS manifestation of VZV is acute cerebellar ataxia. The symptoms include fever, vomiting, and ataxia. This condition is considered benign and self limited and there is no evidence that antiviral therapy is useful $[26,27]$. VZV encephalitis is very rare and occurs more frequently in immunocompromised patients and children $[28,29]$. The pathologic basis of VZV encephalitis is a vasculopathy of large and small cerebral arteries [30,31]. MRI may show one or multiple small or large brain infarcts, but the findings are not specific [29]. CT scan may be normal or show non-specific findings as well [29]. Diagnosis is based upon the history of VZV or herpes zoster rash, usually few weeks before encephalitic symptoms, and demonstration of specific antibodies, antigens, or nucleic acids of VZV by PCR in CSF samples [27,29].

Although there are no specific clinical trials evaluating the efficacy of acyclovir, this drug has been used in the treatment of VZV encephalitis [27-30]. In immunocompromised patients acyclovir is given intravenously at a dose of $10 \mathrm{mg} /$ Kg every 8 hours for at least 10 days [29]. In immunocompetent patients different schedules have been used including oral treatment [30]. The use of corticoids has been proposed for VZV encephalitis treatment in order to reduce cerebral edema but there are no controlled studies supporting their use [2].

\section{Arthropod-Borne Viral Encephalitis}

Several arthropod-borne viruses (arboviruses) are associated with encephalitis. The most important CNS diseases are West-Nile virus encephalitis, Japanese encephalitis, Saint Louis encephalitis, Murray Valley encephalitis, and CNS manifestations associated with dengue [32]. The arbovirus reaches the CNS after bloodstream dissemination and blood-brain barrier crossing. After invading the CNS they determine diffuse encephalitis [32].

Some outbreaks of arbovirus encephalitis have been described in Brazil, such as Rocio and Ilheus [32]. Rocio virus was related with an encephalitis epidemic in São Paulo in the 1970s with nearly 1,000 affected individuals [33]. The complete genomic characterization of this virus isolated from a fatal case was recently published [34]. Three cases of Saint Louis encephalitis were also described in Brazil [35-37].

West Nile virus has reached the New World in 1999. At that time an outbreak was registered in United States. Since then there have been an increasing number of cases in North, Central and South Americas [38,39]. However, this infection has not been reported in Brazil.

Dengue virus causes the most frequent human arboviral disease, and this infection has a higher incidence during summer months. Dengue became a very common disease in Brazil, with more than 4 million of cases registered between 1986 and 2006 [40]. The involvement of CNS in dengue infection has been reported, but its frequency has not been established yet [41-49]. As recently reported by Domingues et al., the most frequent manifestation of CNS involvement in acute dengue virus infection is mental confusion as part of diffuse encephalitis, usually with good prognosis [50]. It is still unclear whether such manifestations result from metabolic imbalance, immune-mediated tissue damage or direct viral invasion of the CNS [50]. The same authors have demonstrated that dengue virus may actively invade the CNS during acute infection, but it is uncertain whether this process is responsible 
for symptoms [50]. The diagnosis of this infection relies on epidemiological data and specific laboratory tests including antibodies, antigens or nucleic acids detection [51]. There are not many systematic studies of neuroimaging findings in dengue CNS involvement. Routine CSF analysis is usually unrevealing, but may disclose mild pleocytosis [50]. As described in the study of Domingues et al., the CSF viral load is very low and therefore nucleic acids are usually not detected in CSF samples [50].

There are no specific antiviral agents for the treatment of CNS dengue and other CNS arboviroses. The management of such diseases is based on general clinical support, including fluid and electrolytes replacement. Attention should be paid to the control of potential neurological complications, such as seizures and CNS bleeding. If such abnormalities occur the patient should be transferred immediately to an intensive care unit to receive anticonvulsant drugs and intracranial hypertension control measures [32]. A special care should be taken in the management of pain in patients with dengue. These patients can not take acetylsalicylic acid for pain relief due to an increased risk of bleeding. Other analgesics, such as paracetamol and acetaminofen, should be used in this condition [52].

\section{Enterovirus Encephalitis}

Enteroviruses are commonly associated with meningitis and eventually with diffuse or focal encephalitis [53,54]. The diagnosis should be suspected in patients with systemic manifestations of an enterovirus infection such as rash and diarrhea. The best diagnostic confirmatory approach is the PCR of CSF samples [54]. The most frequent encephalitis associated enterovirus found in United States is Coxsackie virus B5, followed by Echovirus 18 and 6 [55]. In Brazil there are no specific data on enterovirus encephalitis but in a study from 1998 to 2003 the most frequently isolated virus in enterovirus meningitis was Echovirus 30 [56]. Enterovirus 71 is a common cause of hand, foot, and mouth disease and sometimes causes encephalitis $[57,58]$. There have been some reports of isolation of enterovirus 71 in Brazilian children [59-61].

Although there are reports of treatment of enterovirus encephalitis with pleconaril, there is not conclusive evidence of the efficacy of such treatment. Management of such cases is based on the control of intervenient symptoms [62-65].

\section{Cytomegalovirus}

Cytomegalovirus (CMV) is associated with opportunistic infections of the CNS and peripheral nervous system [66]. There are two distinct forms of CMV encephalitis. The first is CMV ventriculoencephalitis and the second is a more indolent clinical picture associated with microglial nodules and parenchimal necrosis of the brain [67]. CMV ventriculoencephalitis usually has an abrupt onset with progressive mental confusion and lethargy. Neuroradiological findings are non specific and include ventriculitis, hydrocephalus, and rarely mass-effect lesions [67]. The diagnosis can be supported by CSF analysis with CMV culture or PCR [66].

The antiviral agents for CMV are ganciclovir, foscarnet and valganciclovir. In patients with AIDS the proper use of antiretroviral drugs can prevent CMV disease by increasing CD4 count above 100 cells/ $\mathrm{mm}^{3}$. If CMV encephalitis develops ganciclovir is the recommended therapy and should be given at a maintenance dose while the CD4 is bellow 100 cells $/ \mathrm{mm}^{3}$. If oral therapy is feasible, valganciclovir may be preferable. Foscarnet should be restricted to ganciclovir resistant infections due to the high toxicity of this drug $[66,68,69]$.

\section{Acute Disseminated Encephalomyelitis (ADEM)}

ADEM is an auto-immune disorder of the CNS preceded by a viral infection or a vaccination that affects predominantly the white matter of the brain and the spinal cord. It is usually a monophasic disorder. In few cases, it can assume a recurrent pattern. The neurological picture usually begins a few days to a few weeks after a history of infection or vaccination [70]. Clinically the most common findings are a wide range of localizing symptoms. Mental status involvement resembling diffuse encephalitis may be present. Since there are no specific laboratory markers for ADEM, the neuroimaging methods, especially MRI, are extremely relevant. MRI reveals multiple, asymmetric, and large signal abnormalities in the CNS [71]. Acute hemorrhagic leukoencephalitis [AHL] of Weston Hurst is an aggressive and hemorrhagic variant of ADEM usually triggered by a respiratory infection [72,73].

The proposed treatments for ADEM include immunossupressive agents. High doses of steroids are the most used therapy for ADEM. Intravenous methylprednisolone (10-30 mg/Kg/day up to $1 \mathrm{~g} /$ day for three to five days) followed by careful steroid taper is usually recommended. Intravenous Immunoglobulin (IVIG) is an alternative treatment and it is given in a total dose of $2 \mathrm{~g} / \mathrm{Kg}$, administered over 5 days. There have been some reports of plasma exchange in the treatment of ADEM when steroids and IVIG have failed [71].

\section{Practical Approach to Viral Encephalitis in the Emergence Room}

Acute viral or postinfectious encephalitis usually present with headache, malaise and altered level of consciousness. Seizures and focal neurological signs are often seen. In fact neurological signs are usually preceded by unspecific systemic symptoms. Some other clinical information can be of great value in the approach to viral encephalitis, such as the history of a skin rash, diarrhea, respiratory infections, recent travel history, and information about epidemics in the area where the patient lives.

The first step in the approach of a patient with suspected acute viral encephalitis is the differential diagnosis with diseases that actually mimic acute viral encephalitis. For instance, in a prospective study in 432 patients, Whitley et al. have confirmed the diagnosis of HSE in only $45 \%$ of the 
Figure 1. Initial evaluation of suspected acute viral encephalitis.

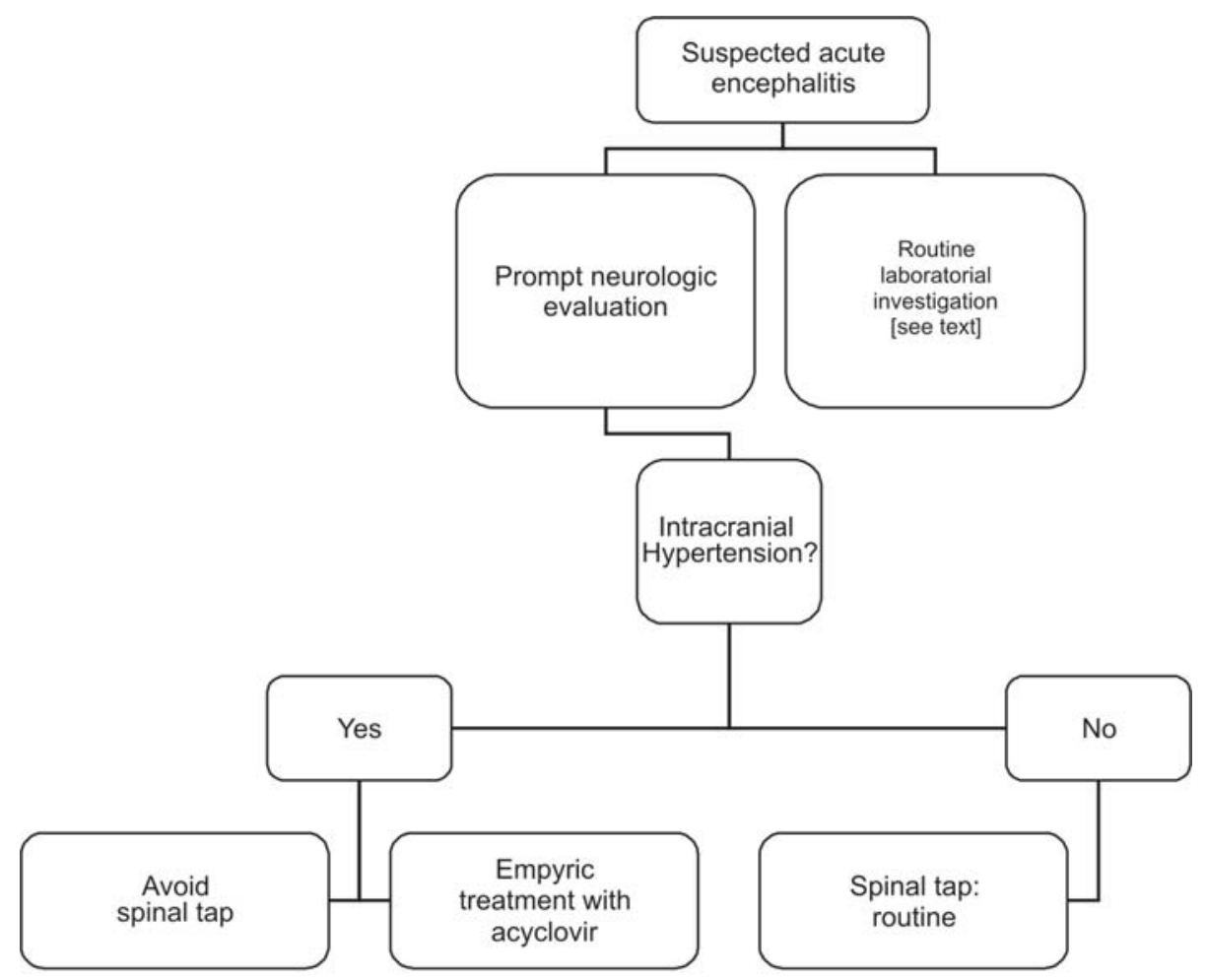

suspected cases. Bacterial and fungal infections, tumors, vascular diseases, and metabolic diseases were initially mistaken as HSE and the precise diagnosis was established with brain biopsy [74]. With the development of new imaging and laboratorial techniques, brain biopsy has been abandoned as a routine method in the diagnosis of acute encephalitis. In a more recent study using only noninvasive methods, Domingues et al. have evaluated 49 cases of suspected acute encephalitis. In only 18 HSE diagnosis was confirmed by CSF PCR. Bacterial infections, drug toxicity, neurocysticercosis, vascular disorders and autoimune disorders were diagnosed in other 18 patients by using neuroimaging and laboratorial noninvasive methods [9].

The routine laboratorial analysis in such cases must include: 1) complete blood cells count, 2) liver enzymes, 3) creatinine, 4) creatinine phosphokinase, 5) electrolytes, 6) blood culture, 7) anti-HIV, 8) anti-nuclear antibodies, 9) antidengue IgM, and 10) VDRL. Cerebrospinal fluid analysis is essential in the approach of these patients. Spinal tap should be performed as soon as possible. However, a great care is required in order to avoid uncal herniation in patients with severe intracranial hypertension, especially if there is a space occupying lesion. For this reason a CT scan should be routinely obtained before spinal tap is performed [2]. In many Brazilian regions it is not possible to promptly obtain a CT scan. If this is the case, the suspected case should be clinically evaluated for the presence of signs of intracranial hypertension. If the patient presents significant reduction in the level of consciousness, localizing signs, papilledema, or anysocoria, spinal tap should be precluded. Another concern about spinal tap is the possibility of thrombocytopenia and hence the risk of spine bleeding, especially in patients with acute dengue infection. In cases in which CSF can not be obtained, it is essential to evaluate the epidemiological and routine laboratorial data. If they are not evidence of an alternative diagnosis, such as a bacterial, fungal or parasitic infection, a vascular disorder or a tumor, empirical treatment with intravenous acyclovir should be immediately given [21] (Figure 1). This is supported by the fact that HSE is the most frequent acute viral encephalitis and HSE is a treatable condition. If there is no improvement with acyclovir, a neuroimaging exam should be tried, even if it is necessary to transfer the patient to a tertiary care center where neuroimaging techniques are available.

In tertiary care services MRI should be performed after or instead of CT scan. MRI is much more sensitive for brain abnormalities in encephalitis than CT [12]. Another advantage of MRI is that it is the best diagnostic tool to distinguish between viral encephalitis and ADEM [70]. The Figure 2 presents the management approach according to the neuroimaging results.

CSF should be submitted to routine analysis, bacterial and fungal cultures, and CSF PCR. The Figure 3 lists the main possible etiologies according to the CSF pattern. At present it is possible to investigate concomitantly the genome of several viruses in the CSF, including HSV, VZV, CMV, and enterovirus, 
Figure 2. Possible etiologies according to the neuroimaging result. Neuroimaging usually shows non specific abnormalities but CT or MRI lesions may be extremely useful to guide the laboratorial investigation that may precisely establish the etiologic diagnosis (2). $\mathrm{CMV}=$ cytomegalovirus, $\mathrm{VZV=varicella-zoster} \mathrm{virus,} \mathrm{ADEM=acute} \mathrm{disseminated} \mathrm{encephalomyelitis.}$

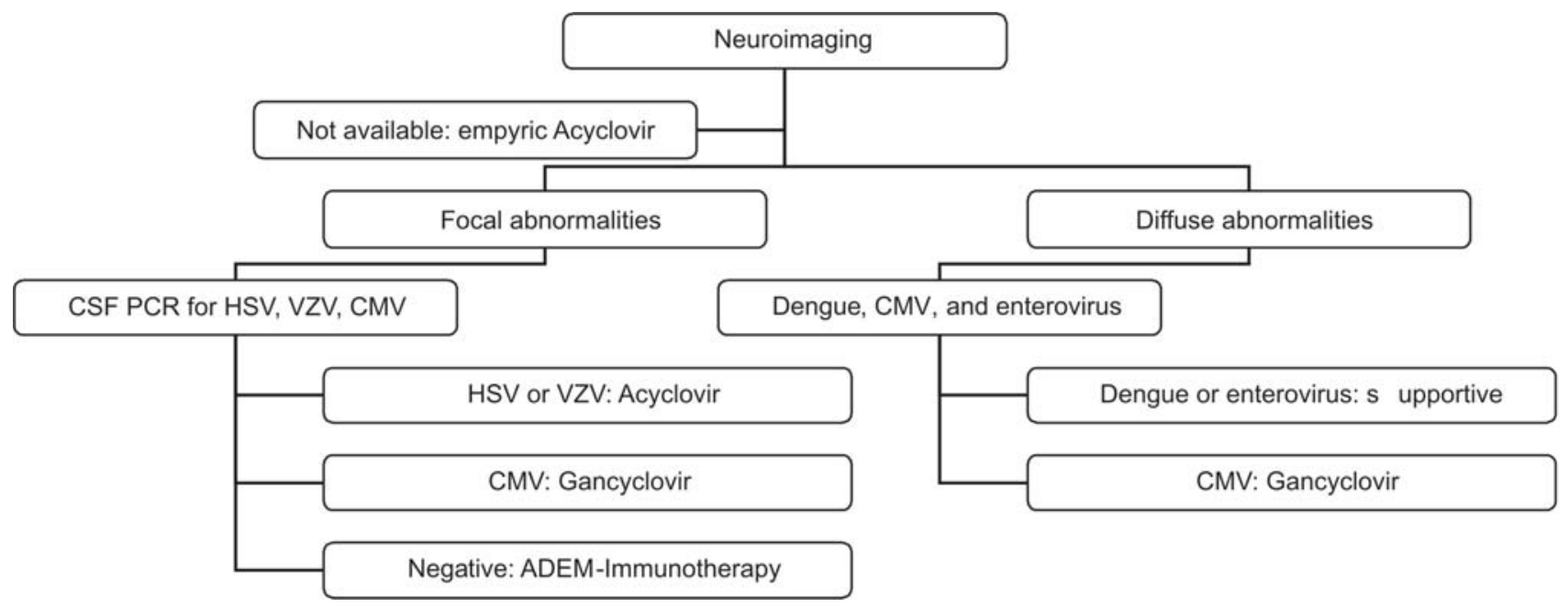

Figure 3. Possible etiologies according to the CSF pattern. CSF pattern is not specific but is extremely useful to guide further laboratorial tests that may precisely define the etiologic diagnosis (2). CMV= cytomegalovirus, VZV=varicella-zoster virus, ADEM=acute disseminated encephalomyelitis.

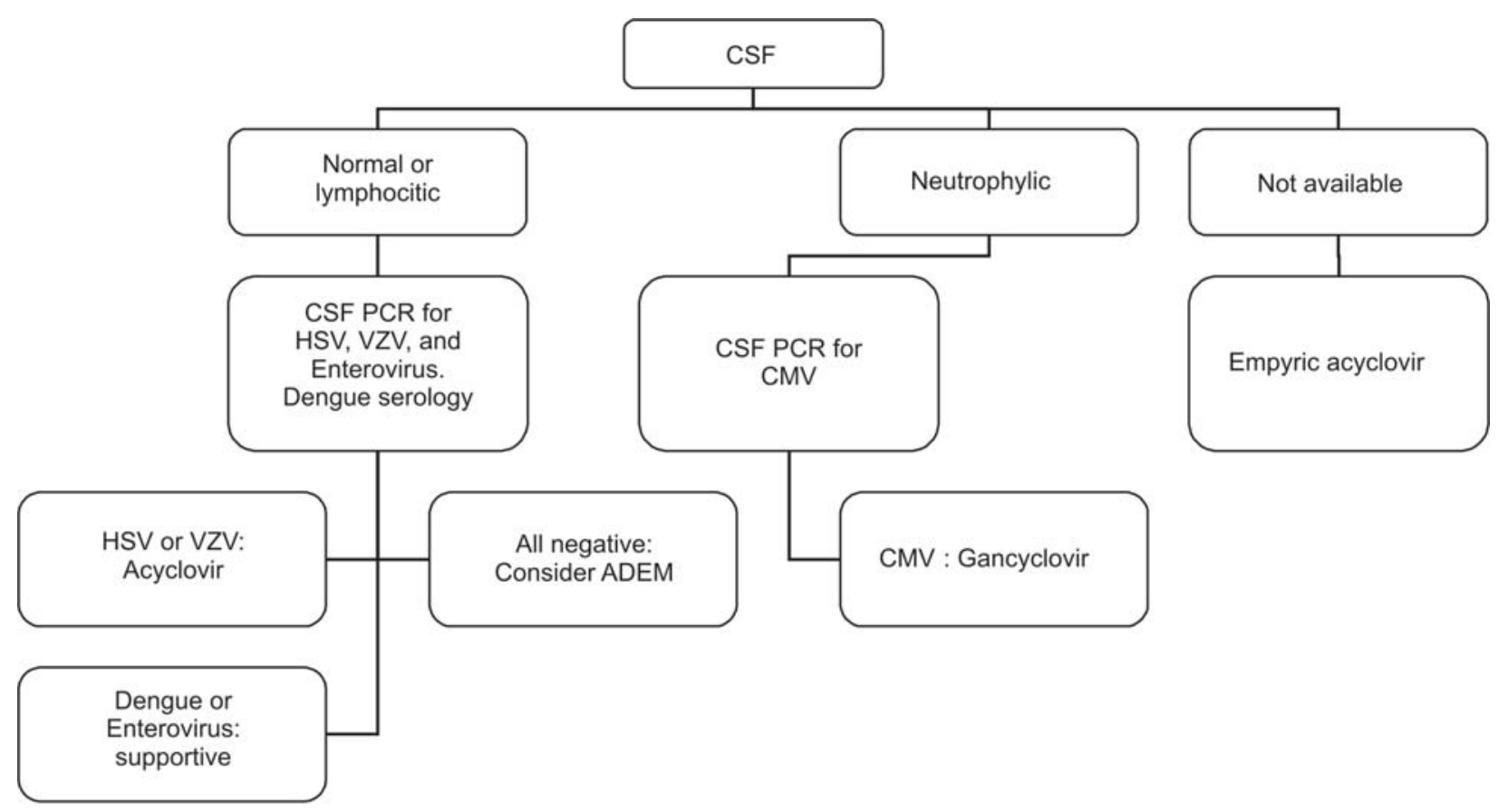

by using PCR or multiplex PCR [75-79]. If this technology is not available or if it is positive for HSV or VZV intravenous acyclovir should be given. Acyclovir should never be interrupted unless a differential diagnosis is undoubtedly established with the laboratorial or neuroimaging methods.

Regarding immunocompromised patients, the approach may differ. In HIV patients with acute encephalitis suspicion,
CMV must be considered and gancyclovir started. These patients may present retinal abnormalities that can be seen by fundoscopic examination [66].

\section{Concluding Remarks}

Acute viral encephalitis represents a major medical problem. New antiviral therapies, intensive care procedures, and 
immunomodullatory agents have significantly improved the prognosis of patients with acute viral encephalitis. However, fatal outcomes and severe neurological sequelae are frequently seen. The most crucial aspects in the management of acute viral encephalitis are the early diagnosis and treatment. It is clear that unfavorable outcomes may occur even when a correct diagnosis and adequate therapy are given. Nevertheless, the initial assistance in the emergence room is the more decisive aspect in the approach of these patients and impacts directly on their prognosis. In the future, we hope that the development of new antiviral drugs with a better CNS penetration, antiviral activity, and lower toxicity may improve even more the prognosis of such diseases.

\section{References}

1. Stone M.J., Hawkins C.P. A medical overview of encephalitis. Neuropsychol Rehabil: 2007;17: 429-49.

2. Solomon T., Hart I.J., Beeching N.J. Viral encephalitis: a clinician's guide. Pract Neurol 2007;7: 288-305.

3. Sejvar J.J. The evolving epidemiology of viral encephalitis. Curr Opin Neurol 2006; 19:350-7.

4. Solomon T. Exotic and emerging encephalitides. Curr Opin Neurol 2003;16:411-418.

5. Domingues R.B., Tsanaclis A.M.C., Pannuti C.S., Mayo M., Lakeman F.D. Evaluation of the range of clinical presentations of herpes simplex encephalitis by using polymerase chain reaction assay of cerebrospinal fluid samples. CID 1997;25:86-91.

6. Lewis P., Glaser C.A. Encephalitis. Pediatr Rev 2005;26:353-63.

7. Smith M.G., Lennete E.H., Reames H.R. Isolation of the virus of herpes simplex and demonstration of intranuclear inclusions in a case of acute encephalitis. Am J Pathol 1941;17:55-68

8. Cassady K.A., Whitley R.J. Pathogenesis and pathophysiology of viral infections of the cntral nervous system. In: Scheld WM, Whitley RJ, Marra C, eds. Infections of the Central Nervous System, Lippincott Williams and Wilkins, 2004.

9. Kimberlin D.W. Management of HSV encephalitis in adults and neonates: diagnosis, prognosis and treatment. Herpes 2007;14:11-6.

10. Nahmias A.J., Whitley R.J., Visintine A.N., Takei Y., Alford C.A. Herpes simplex encephalitis: laboratory evaluations and their diagnostic significance. JID 1982;45:829-36.

11. Aurelius E., Johansson B., Sköldenberg B., Forsgren M. Encephalitis in immunocompetent patients due to herpes simplex virus type 1 or 2 as determined by type-specific polymerase chain reaction and antibody assays of cerebrospinal fluid. J Med Virol 1993;39:179-86

12. Domingues R.B., Fink M.C.D., Tsanaclis A.M.C., de Castro C.C., Cerri C.C., Mayo M.S., Lakeman F.D. Diagnosis of herpes simplex encephalitis by magnetic resonance imaging and polymerase chain reaction assay of cerebrospinal fluid. J Neurol Sci 1998; $157: 148-153$.

13. Lakeman F.D., Whitley R.J. Diagnosis of herpes simplex encephalitis: application of polymerase chain reaction to cerebrospinal fluid from brain-biopsed patients and correlation with disease. JID 1995;171:857-63.

14. Domingues R.B., Lakeman F.D., Pannuti C.S., Fink M.C.D., Tsanaclis A.M.C. Advantage of polymerase chain reaction in the diagnosis of herpes simplex encephalitis: presentation of five atypical cases. Scand J Infect Dis 1997;29:229-31

15. Domingues R.B., Mayo M., Lakeman F.D., Whitley R.J. Application of competitive PCR to cerebrospinal fluid samples from patients with herpes simplex encephalitis. J Clin Microbiol 1998;36:2229-2234.

16. Sköldenberg B., Alestig K., Burman L., Forkman A., Lövgren K., Norrby Y., Stiernstedt G., Forsgren M., Bergström T., Dahlqvist E., Frydén A., Norlin K., Olding-Stenkvist E., Uhnoo I., De Vahl K. Acyclovir versus vidarabine in herpes simplex encephalitis. Lancet 1984;2:707-11.
17. Whitley R.J., Alford C.A., Hirsh M.S., Schooley R.T., Luby J.P., Aoki F.Y., Hanley D., Nahmias A.J., Soong S.J. Vidarabine versus acyclovir therapy in herpes simplex encephalitis. N Engl J Med 1986;314:144-9.

18. Périgaud C., Gosselin G., Imbach J. Nucleoside analogues as chemotherapeutic agents: a review. Nucleosides and nucleotides 1992;11:2-4.

19. Whitley R.J., Gnann J.W. Acyclovir: a decade later. N Engl J Med 1992;327:782-9

20. O’Brien J.J., Campoli-Richards D.M. Acyclovir. An updated review of its antiviral activity, pharmacokinetic properties and therapeutic efficacy. Drugs 1989;37:233-309.

21. Whitley R.J., Lakeman F.D. Herpes simplex virus infections of the central nervous system: therapeutic and diagnostic considerations. CID 1995;20:414-20.

22. Saldanha J., Sutton R.N.P., Gannicliffe A., Farragher B., Fitzhaki R. Detection of HSV-1 DNA by in situ hybridization in human brain after immunossupression. J Neurol Neurosurg Psychiatry 1986;49:613-9.

23. Gateley A., Genger R.M., Johnson P.C., Kit S., Ptsuka H., Kohl S. Herpes simplex virus type 2 meningoencephalitis resistant to acyclovir in a patient with AIDS. JID 1990;161:711-5.

24. De Clercq E., Field H.J. Antiviral prodrugs - the development of successful prodrug strategies for antiviral chemotherapy. $\mathrm{Br} \mathrm{J}$ Pharmacol 2006;147:1-11.

25. MacDougall C., Guglielmo B.J. Pharmacokinetics of Valaciclovir. J Antimicrob Chemother 2004;53:899-901.

26. Bale J.F. Jr. Human herpesviruses and neurological disorders of childhood. Semin Pediatr Neurol 1999;6:278-87.

27. Steiner I., Kennedy P.G., Pachner A.R. The neurotropic herpes viruses: herpes simplex and varicella-zoster. Lancet Neurol 2007;6:1015-28.

28. Flamholc L. Neurological complications in herpes zoster. Scand J Infect Dis Suppl. 1996;100:35-40.

29. Toledo P.V., Pellegrino L.N., Cunha C.A. Varicella-zoster virus encephalitis in an AIDS patient. Braz J Infect Dis 2004;8:225-228.

30. McKelvie P.A., Collins S., Thyagarajan D., Trost N., Sheorey H., Byrne E. Meningoencephalomyelitis with vasculitis due to varicella zoster virus: a case report and review of the literature. Pathology 2002;34:88-93.

31. Mathis S., Gil R., Neau J.P. Neurological complications of Herpes zoster. Rev Neurol [Paris. 2006;162[8-9]:879-87.

32. Solomon T., Whitley R.J. Arthropod borne viral encphalitis. In: Scheld WM, Whitley RJ, Marra C, eds. Infections of the Central Nervous System, Lippincott Williams and Wilkins, 2004.

33. Coimbra T.L., Santos R.N., Petrella S., Nagasse-Sugahara T.K., Castrignano S.B., Santos C.L. Molecular characterization of two Rocio flavivirus strains isolated during the encephalitis epidemic in São Paulo State, Brazil and the development of a one-step RT-PCR assay for diagnosis. Rev Inst Med Trop Sao Paulo 2008;50:89-94.

34. Medeiros D.B., Nunes M.R., Vasconcelos P.F., Chang G.J., Kuno G. Complete genome characterization of Rocio virus [Flavivirus: Flaviviridae], a Brazilian flavivirus isolated from a fatal case of encephalitis during an epidemic in Sao Paulo state. J Gen Virol 2007;88:2237-46.

35. Rocco I.M., Santos C.L., Bisordi I., Petrella S.M., Pereira L.E., Souza R.P., Coimbra T.L., Bessa T.A., Oshiro F.M., Lima L.B., Cerroni M.P., Marti A.T., Barbosa V.M., Katz G., Suzuki A. St. Louis encephalitis virus: first isolation from a human in São Paulo State, Brazil. Rev Inst Med Trop Sao Paulo 2005;47:281-5.

36. Santos C.L., Sallum M.A., Franco H.M., Oshiro F.M., Rocco I.M. Genetic characterization of St. Louis encephalitis virus isolated from human in São Paulo, Brazil. Mem Inst Oswaldo Cruz. 2006;101:57-63.

37. Ré V., Spinsanti L., Farías A., Díaz A., Vázquez A., Aguilar J., Tenorio A., Contigiani M. Reliable detection of St. Louis encephalitis virus by RT-nested PCR. Enferm Infecc Microbiol Clin 2008;26:10-5. 
38. Davis L.E., Beckham J.D., Tyler K.L. North American encephalitis arboviruses. Neurol Clin 2008;26:727-57.

39. Davis L.E., DeBiasi R., Goade D.E., Haaland K.Y., Harrington J.A., Harnar J.B., Pergam S.A., King M.K., DeMasters B.K., Tyler KL. West Nile virus neuroinvasive disease. Ann Neurol 2006; $60: 286-300$.

40. Nogueira R.M., de Araújo J.M., Schatzmayr H.G. Dengue virus in Brazil, 1986-2006. Rev Panam Salud Publica 2007;22:358-63.

41. Salomon T., Mallewa M. Dengue and other emerging Flaviviruses. J Infect 2001;42:104-15.

42. Lum L.C.S., Lam S.K., Choy Y.S., George R., Harun F. Dengue encephalitis: a true entity? Am J Trop Med Hyg 1996;54:256-9.

43. Hommel D., Talarmin A., Deubel V., Reynes J.M., Drouet M.T., Sarthou J.L., et al. Dengue encephalitis in French Guiana. Res Virol 1998; 149:235-8.

44. Salomon T., Dung N.M., Vaughn D.W., Kneen R., Thao L.T., Raengsakulrach B., et al. Neurological manifestations of dengue infection. Lancet 2000; 355:1053-9.

45. George R., Lam S.K. Dengue virus infection-the Malaysian experience. Ann Acad Med Singapore 1997;26:815-9.

46. Pancharoen C., Thisyakorn U. Neurological manifestations in Dengue patients. Southeast Asian J Trop Med Public Health 2001;32:341-5.

47. Strobel M., Lamaury I., Contamin B., Jarrige B., Perez J.M., Steck A.J., et al. Fiévre dengue á expression neurologique. Ann Med Interne 1999;150:79-82.

48. Vasconcelos P.F., da Rosa A.P., Coelho I.C., Menezes D.B., da Rosa E.S., Rodrigues SG, et al. Involvement of the central nervous system in dengue fever: three serologically confirmed cases from Fortaleza, Ceará, Brazil. Rev Inst Med Trop São Paulo 1998;40:35-9.

49. Kankirawatana P., Choquephaibulkit K., Puthavathana P., Apintanapong S., Pongthapisit V. Dengue infections presenting with central nervous system manifestation. J Child Neurol 2000; $15: 544-7$.

50. Domingues R.B., Kuster G.W., Onuki-Castro F., Souza V.A., Levi J.E., Pannuti C.S. Involvement of central nervous system in patients with dengue virus infections. J Neurol Sci 2008;267:36-40.

51. Souza V.A.U.F., Tateno A.F., Oliveira R.R., Domingues R.B., et al. Sensitivity and specificity of three ELISA-based assays for discriminating primary fom secondary acute dengue infections. J Clin Virol 2007;39:230-233

52. Domingues R.B., Kuster G.W., Onuki-Castro F., et al. Headache features in patients with dengue virus infections. Cephalalgia 2006;26:879-882.

53. Steiner I., Budka H., Chaudhuri A., Koskiniemi M., Sainio K., Salonen O., Kennedy P.G. Viral encephalitis: a review of diagnostic methods and guidelines for management. Eur J Neurol 2005;12:331-43.

54. Romero J.R., Kimberlin D.W. Molecular diagnosis of viral infections of the central nervous system. Clin Lab Med 2003;23:843-65.

55. Tavakoli N.P., Wang H., Nattanmai S., Dupuis M., Fusco H., Hull R. Detection and typing of enteroviruses from CSF specimens from patients diagnosed with meningitis/encephalitis. J Clin Virol 2008;43:207-11.

56. Dos Santos G.P., Skraba I., Oliveira D., Lima A.A., de Melo M.M., Kmetzsch C.I., da Costa E.V., da Silva E.E. Enterovirus meningitis in Brazil, 1998-2003. J Med Virol 2006;78:98-104.

57. Hamaguchi T., Fujisawa H., Sakai K., Okino S., Kurosaki N., Nishimura Y., Shimizu H., Yamada M. Acute encephalitis caused by intrafamilial transmission of enterovirus 71 in adult. Emerg Infect Dis 2008;14:828-30.

58. Pérez-Vélez C.M., Anderson M.S., Robinson C.C., McFarland E.J., Nix W.A., Pallansch M.A., Oberste M.S., Glodé M.P. Outbreak of neurologic enterovirus type 71 disease: a diagnostic challenge. Outbreak of neurologic enterovirus type 71 disease: a diagnostic challenge. Clin Infect Dis 2007;45:950-7.

59. Lamarão L.M., Maciel A.M., Gomes M.L. First isolation of enterovirus 71 [EV-71] from Northern Brazil. Braz J Infect Dis 2003; 7:278-81.
60. Gomes M.L., de Castro C.M., Oliveira M.J., da Silva E.E. Neutralizing antibodies to enterovirus 71 in Belém, Brazil. Mem Inst Oswaldo Cruz 2002;97:47-9.

61. Takimoto S., Waldman E.A., Moreira R.C., Kok F., Pinheiro F.P., Saes S.G., Hatch M., de Souza D.F., Carmona R.C., Shout D., de Moraes J.C., Costa A.M. Enterovirus 71 infection and acute neurological disease among children in Brazil [1988-1990]. Trans R Soc Trop Med Hyg 1998;92:25-8.

62. Pevear D., Tull T., Seipel M., Groarke J. Activity of pleconaril against enteroviruses. Antimicrob Agents Chemother 1999;43: 2109-15.

63. Florea N., Maglio D., Nicolau D. Pleconaril, a novel antipicornaviral agent. Pharmacotherapy 2003;23: 339-48.

64. Rotbart H.A., Webster A.D. Pleconaril Treatment Registry Group. Treatment of potentially threatening enterovirus infections with pleconaril. Clin Infect Dis 2001;32:228-35.

65. Pevear D.C., Tull T.M., Seipel M.E., Groarke J.M. Activity of pleconaril against enteroviruses. Antimicrob Agents Chemother 1999;43:2109-2115.

66. Griffiths P. Cytomegalovirus infection of the central nervous system. Herpes 2004;11 Suppl 2:95A-104A.

67. Vancíková Z., Dvorák P. Cytomegalovirus infection in immunocompetent and immunocompromised individuals-a review. Curr Drug Targets Immune Endocr Metabol Disord 2001; 1:179-87.

68. Anduze-Faris B.M., Fillet A.M., Gozlan J., et al. Induction and maintenance therapy of cytomegalovirus central nervous system infection in HIV-infected patients AIDS 2000;14:517-24.

69. Julin J.E., van Burik J.H., Krivit W., Webb C., Holman C.J., Clark H.B., Balfour H.H. Jr. Ganciclovir-resistant cytomegalovirus encephalitis in a bone marrow transplant recipient. Transpl Infect Dis 2002;4:201-6.

70. Tenembaum S., Chitnis T., Ness J., Hahn J.S., International Pediatric MS Study Group. Acute disseminated encephalomyelitis. Neurology 2007;68[16 Suppl 2]:S23-36.

71. Tenembaum S., Chamoles N., Fejerman N. Acute disseminated encephalomyelitis: a long-term follow-up study of 84 pediatric patients. Neurology 2002;59:1224-31.

72. Klein C.J., Wijdicks E.F., Earnest F. 4th. Full recovery after acute hemorrhagic leukoencephalitis [Hurst's disease]. J Neurol 2000;247:977-9.

73. Martins H.M., Teixeira A.L. Jr, Lana-Peixoto M.A., Brazilian Committee for Treatment and Research in Multiple Sclerosis. Acute hemorrhagic leukoencephalitis mimicking herpes simplex encephalitis: case report. Arq Neuropsiquiatr 2004;62:139-43.

74. Whitley R.J., Cobbs C.G., Alford C.A., Soong S.J., Hirsch M.S., Connor J.D., Corey L., Hanley D.F., Levin M., Powell D.A. Diseases that mimic herpes simplex encephalitis: diagnosis, presentation, and outcome. JAMA 1989;262:234-9.

75. Bergallo M., Costa C., Margio S., Sidoti F., Terlizzi M.E., Cavallo R. Development of a multiplex polymerase chain reaction for detection and typing of major human herpesviruses in cerebrospinal fluid. Can J Microbiol 2007;53:1117-22.

76. McIver C.J., Jacques C.F., Chow S.S., Munro S.C., Scott G.M., Roberts J.A., Craig M.E., Rawlinson W.D. Development of multiplex PCRs for detection of common viral pathogens and agents of congenital infections. J Clin Microbiol 2005;43:510210.

77. Boriskin Y.S., Rice P.S., Stabler R.A., Hinds J., Al-Ghusein H., Vass K., Butcher P.D. DNA microarrays for virus detection in cases of central nervous system infection. J Clin Microbiol 2004;42:5811-8.

78. Debiasi R.L., Tyler K.L. Molecular methods for diagnosis of viral encephalitis. Clin Microbiol Rev 2004;17:903-25.

79. Calvario A, Bozzi A, Scarasciulli M, Ventola C, Seccia R, Stomati D, Brancasi B. Herpes Consensus PCR test: a useful diagnostic approach to the screening of viral diseases of the central nervous system. J Clin Virol 2002;25 Suppl 1:S71-8. 